\title{
Novas formas de relacionamento: fim do amor romântico ou um novo amor-consumo?
}

\author{
Cláudia Samuel Kessler \\ Doutoranda em Antropologia Social na Universidade Federal do Rio Grande do Sul, \\ Porto Alegre, Rio Grande do Sul, Brasil \\ jornalista24h@hotmail.com
}

\begin{abstract}
Resumo O presente artigo aborda o conceito de amor-consumo e outras expressões de afeto e sexualidade na contemporaneidade, tendo como base o pensamento econômico sobre os atuais relacionamentos que se contrapõem ao ideal do amor romântico. O texto, de abordagem antropológica, apresenta relatos de integrantes de um novo movimento social autointitulado Relações Livres, que entende o indivíduo como gerenciador de suas relações sexuais e amorosas, e é contrário à monogamia.
\end{abstract}

Palavras-chave: amor, consumo, relacionamentos, capitalismo, monogamia.

A mor. Uma única palavra, mas que suscita diversas interpretações e emoções. Amor, sentimento difícil de definir, embora expressão frequentemente utilizada em diversos relacionamentos, estejam eles na fase inicial ou alicerçados em anos de convivência. $\mathrm{O}$ amor do qual se tratará neste artigo não será conceitualmente definido, mas será geograficamente localizado na porção ocidental do globo, especificamente no território brasileiro. A justificativa para a opção de não definir o amor nas próximas linhas está relacionada às diversas conceituações que este pode ter ${ }^{1}$ (ou até mesmo não ter, como no caso dos integrantes do movimento social autointitulado Relações Livres).

Em nome do amor, historicamente registra-se o início de diversas batalhas travadas, reinos destruídos e homicídios justificados. As expressões amorosas são tão diversas e amplas que, se fôssemos tentar entender o contexto das utilizações da expressão amor, seria necessário nos contentar com uma tese inacabada, escrita e reescrita infinitamente. O amor não só é dito como é capaz de ultrapassar fronteiras, mas também pode ser um dos motores que sustenta a atual economia capitalista. Relacionamentos são formados e terminados em nome desse sentimento.

Corriqueiramente, percebe-se nos discursos de bares ou da rua (bem como em discussões nas redes sociais) que a nossa sociedade banalizou a enunciação da expressão amor sem que se consiga defini-la ou que se saiba em quais momentos pode ser proferida. De que amor se fala? O que é o amor? Como é sentido e expressado? Mesmo sem

1. Mezan (2008) elenca seis diferentes formas de amor: 1) ennóia (devoção); 2) ágape (desinteressado); 3) storgé (ternura); 4) páthos (desejo); 5) cháris (caridade); 6) mania (paixão desenfreada). Independentemente de quantas formas possam ser elencadas, deve-se atentar que as gradações e diferenciações estão relacionadas não apenas aos contextos culturais e históricos, mas às subjetividades dos agentes sociais envolvidos nas trocas de sentimentos e afetos. 
definições específicas, pode-se afirmar que quando se trata de amor, assim como da complexidade humana, não há fórmulas.

Entretanto, poder-se ia entender essa nova postura apenas como uma ampliação generalizada de seu uso, abarcando novas significações e apontando para novas expressões de um sentimento que se pensava ser único e normativamente expressado.

O amor, simultaneamente, procede a palavra e precede a palavra. Trata-se de um interessante problema, uma vez que há culturas em que não se fala de amor. Mas mesmo nestas culturas, em que não se fala de amor e que o amor não emergiu enquanto noção, será que, verdadeiramente, não existe amor? Ou será que sua existência decorre do não dito? (Morin, 2008, p. 17)

Não antes sem analisar criticamente as mudanças nos relacionamentos afetivos, poder-se-ia perguntar: por que diversas práticas que antes não eram consideradas como amor, agora o são? Quais foram os grupos abarcados nessa ampliação e que efeitos foram gerados? Poder-se-ia separar afeto, paixão, encantamento e desejo como diferentes formas de expressão do amor? Seriam elas mais intensas, menos intensas, ou quando se trata de amor sua intensidade não pode ser quantificada? Seria o amor um sentimento subjetiva ou socialmente legitimado?

Com este texto não se pretende suprir todas as dúvidas em relação à temática amorosa, entretanto, tais questionamentos auxiliarão a entender algumas mudanças na forma de gerenciamento dos relacionamentos afetivos estabelecidos entre indivíduos adultos e ocidentais na atualidade. A proposta do presente texto é abordar brevemente algumas questões relacionadas ao amor na contemporaneidade e associá-las ao valor econômico e ao consumo que influenciam o sistema econômico atual.

$\mathrm{Na}$ atualidade, a noção de mercado deixou de ser um monopólio dos economistas, passando a ser objeto também de antropólogos, dada a sua variabilidade cultural e social (Zélizer, 1992). Neste trabalho, será brevemente analisada a visão que se tem do amor romântico no sistema capitalista, bem como de alternativas e pontuações sobre a influência de outras formas de relacionamento ditas pós-modernas, contrapostas à prática monogâmica. Elucidar-se-á a temática a partir de Bauman (2004) - o qual afirma existir no mundo pós-moderno uma constante insegurança entre os indivíduos -, que aborda a fragilidade dos laços e a presença dos desejos conflitantes nos relacionamentos pessoais.

Inicialmente, serão abordadas algumas questões conceituais e históricas, e após serão apresentadas algumas das atuais formas de expressão do amor. ${ }^{2} \mathrm{Se}-$ rão também expostas algumas entrevistas realizadas para este trabalho com um movimento social que se contrapõe "à visão hegemônica do amor romântico e monogâmico": a Rede de Relações Livres (RLi). ${ }^{3} \mathrm{O}$ intuito deste material é não apenas o de refletir sobre este tema, mas principalmente assumir um posicionamento crítico. Visões pessoais, científicas e depoimentos serão interligados, com o intuito de produzir a dúvida, gerar a reflexão e (des)organizar/(des) construir conceitos.

Teoricamente, as áreas afetiva e econômica começaram recentemente a ser interligadas: "Ao longo da década de 2000, as linhas de discussão que marcaram os debates sobre as imbricações entre economia, práticas sexuais e sentimentos têm chamado a atenção para como as relações íntimas e pessoais se tornaram mais explicitamente mercantilizadas" (Piscitelli, 2011, p. 537). Procurar-se-á nas páginas seguintes relacionar as novas expressões do amor e do dinheiro, por meio da utilização do termo amor-consumo. ${ }^{4}$ Quando se pensa em sentimentos, procura-se desassociá-los do dinheiro, por tratar-se do dinheiro como algo impessoal ou até mesmo "sujo"; porém, a tarefa do presente texto será demonstrar a imbricação entre essas diferentes áreas. No senso comum, acredita-

2. Ou também, como no movimento Relações Livres, a não utilização da expressão amor, mas o exercício de uma afetividade ainda não nomeada.

3. O presente material possui entrevistas realizadas com quatro homens integrantes da rede Relações Livres (termo que posteriormente será explicado), havendo também discursos elaborados por integrantes da rede de relações não monogâmicas na $1^{a}$ Reunião Nacional das Manifestações Não Monogâmicas, realizada de 17 a 19 de junho de 2011, em Porto Alegre, RS. As entrevistas foram marcadas nos locais de preferência dos entrevistados e seus nomes foram omitidos com o intuito de preservar o anonimato.

4. A reflexão sobre o amor-consumo provém da ideia de que o amor na atualidade em muito está ligado às mudanças sociais, e, dada a rapidez das transformações, talvez seja provável identificarmos a presença de práticas que ainda são denominadas por seus nomes em decorrência do costume, mas que sofreram mudanças substantivas em seu conteúdo. Ou seja, poder-se-ia entender como um processo em que as práticas discursivas e linguísticas dificultassem a visibilidade de mudanças já ocorridas nas práticas sociais. Neste sentido, podem-se entender as mudanças nos relacionamentos como uma inovação que tem interpenetrado nas práticas presentes, visível na "monogamia seriada" (ou seja, a frequente troca de relacionamentos, em que, logo após o término de um, um novo é iniciado, em um processo compulsivo e ininterrupto), que se projeta como uma tentativa de manutenção da monogamia, em face do movimento não monogâmico. A convivência entre ambas as práticas provocam transformações, em uma convivência nem tanto silenciosa, mas negociada. Conforme Corrêa de Lima (2005, p. 49), "se nos reportarmos ao conceito de inovação numa perspectiva cultural, este aparece definido como a fase inicial do processo de mudança, caracterizando-se por combinar elementos familiares com estruturas novas. À inovação segue-se outra fase necessária à concretização da mudança: a de seleção, em que tem lugar a aceitação mútua entre a inovação e o sistema cultural de que ela daí em diante passa a fazer parte". 
-se que o amor dificilmente possa ser mensurado ou quantificado, tal como os bens materiais.

Quando se trata de amor, relacionado ao zelo, por exemplo, "a observação desses cuidados não revela duas esferas radicalmente diferentes, uma antissepticamente econômica e outra reconfortantemente sentimental" (Zélizer, 2009, p. 250). A necessidade de pensar como estão imbricadas essas esferas apresenta-se num contexto ainda mais amplo, o qual abarca não apenas a esfera sentimental, mas também a histórica, a política, a econômica e a social.

A abordagem do tema do amor não apenas engloba o sentimento e as práticas sociais, mas também as estruturas sociais. Conforme Zélizer (2009, p. 237), "os economistas, na verdade, frequentemente dicotomizaram o mundo em mercado e não-mercado, racional e pessoal, eficiente e sentimental, macho e fêmea". No presente artigo, na seção relativa ao amor-consumo, abordar-se-á uma provável existência de um "mercado amoroso", o qual não apenas está relacionado a perdas e ganhos sentimentais, mas também parece mover diversas esferas do sistema capitalista. O amor não apenas é sentimento que move as ações, mas também movimenta investimentos monetários em torno dos relacionamentos: presentes, jantares, cartões, viagens, joias, vestuário e outros mais.

O ser humano não apenas é representante de sua subjetividade, mas também, como produtor-reprodutor da cultura que o cerca, transforma e legitima as ordens e imposições sociais. Exemplo disso é o casamento, o qual é permeado não apenas por interesses pessoais (como a busca da satisfação pessoal), mas também envolve questões legais e sociais que regulam os deveres, as obrigações e os direitos de cada um dos integrantes de um relacionamento.

A aceitação de determinados modos de viver referem-se à abertura ou às mudanças aceitas ou reprimidas pelo grupo social circundante. A obediência, a dedicação, a liberdade ou a expressão do afeto possuem variações também determinadas pelo social e o cultural. Com relação ao casamento, pode-se assim afirmar que ele "representa o interesse social face ao interesse individual do amor e, no seio de outra categoria, a existência e a assistência da nova geração representam o interesse social face à questão pessoal do casamento" (Simmel, 1993, p. 36).

\section{A influência dos contextos históricos}

$\mathrm{Na}$ sociedade brasileira, a monogamia e a heteronormatividade estão presentes nos discursos e na mídia. O desejo tem sido tratado como um "monodesejo", sem a possibilidade de expansão, possibilitando apenas a escolha de um objeto amoroso, ao qual se deve dedicar tempo, afeto e carinho. Os amores paralelos, dessa forma, são tratados como resultantes da infidelidade, da traição, derivados de questões relacionadas ao caráter e à moral do indivíduo. ${ }^{5}$

A humanidade cria instituições, institui a exogamia, as regras de parentesco, prescreve o casamento, proíbe o adultério. Mas é extremamente notável que o desejo e o amor ultrapassam, transgridem normas, regras e interditos: ou bem o amor é muito endógamo e torna-se incestuoso ou é exógamo e torna-se adúltero, traidor do grupo, do clã, da pátria. A selvageria do amor o conduz à clandestinidade e à transgressão. (Morin, 2008, p. 22)

A dificuldade de encontrar, hoje em dia, o que antes era ressaltado pelo "amor romântico" parece ter gerado uma "neurose", uma constante busca por um amor que não se sabe ao certo o que é, para que serve, mas que se deseja "ter a qualquer custo". É algo que muito mais se assemelha a um consumo desmedido, na constante ânsia por saciar a insatisfação pessoal com a "aquisição", posse ou conquista de algo que preencha carências. Por vezes, essa busca por um parceiro ou parceira torna-se um fluxo sucessivo de substituições, de uma "monogamia seriada", ${ }^{6}$ na qual logo após o término de um relacionamento, compulsoriamente, outro é iniciado, fugindo-se da solidão.

Poder-se-ia afirmar, conforme Luhmann (1991, p. 215), que "o caráter trágico já não reside no fato de os amantes não se encontrarem, mas no fato de as relações sexuais gerarem amor e no fato de não

\footnotetext{
5. Uma pesquisa quantitativa promovida pela antropóloga e pesquisadora Mirian Goldenberg, com 1.279 homens e mulheres do Rio de Janeiro, revelou que $60 \%$ dos homens e $47 \%$ das mulheres se confessaram infiéis (Zero Hora, 2009). Percebe-se um significativo aumento das práticas consideradas infiéis, na busca por outros parceiros sexuais ou afetivos sem o consentimento do outro integrante da relação monogâmica. Dessa forma, pode-se indagar até que ponto a monogamia ainda está sendo praticada e de que maneira ela consegue se sustentar discursivamente. Os números claramente revelam um declínio na manutenção de apenas um integrante na relação. Ser infiel, em um panorama em que outros "contratos" matrimoniais/afetivos são aceitos, pode ser sinônimo de que esses outros contratos ainda não sejam bem aceitos socialmente ou que os casais ainda não se sintam prontos para lidar com as consequências que eles teórica e hipoteticamente poderiam gerar.

6. O movimento não monogâmico entende essa prática seriada e contínua como um problema estrutural da monogamia, como tentativa de sua manutenção. Por outro lado, pode-se percebê-lo como uma expressão que objetiva driblar os valores morais da sociedade ocidental atual, a qual divulga valores que apresentam a poligamia ou não monogamia como condutas impróprias aos agentes sociais que desejam manter imagens ligadas à credibilidade.
} 
ser possível viver segundo ele nem libertarmo-nos dele". A busca pelo relacionamento amoroso parece, em grande parte, ser planejada, pensada e construída. Porém, essas construções sofrem a influência de aspectos que envolvem as trajetórias sociais, os ideais e um conjunto de fatores sociais (até mesmo econômicos) que influenciam no contato e na formação desses relacionamentos amorosos.

Esse amor exposto por Luhmann (1991) parece ser o motor da constante geração de angústias, dada a inabilidade de encontrar alguém que satisfaça os desejos e as necessidades projetados. Tal mecanismo assemelha-se ao utilizado nas estratégias de marketing e propaganda atuais, as quais incentivam seus compradores a adquirir um produto que satisfaça as suas "novas necessidades" (necessidades que são constantemente criadas e renovadas).

À inacessibilidade do ser amado cantada em verso e prosa pela literatura soma-se assim a inacessibilidade do ideal: verificando que não podemos corresponder àquilo que ele exige, tentamos de mil maneiras contornar essa impossibilidade, sempre sem sucesso: o resultado são vivências de fracasso e de angústia - e para nos proteger delas, entram em cena as defesas com que conta a nossa estrutura psíquica: negação, cisão, projeção, recalque... (Mezan, 2008, p. 9)

As amarras existentes nos relacionamentos em parte parecem estar relacionadas à normatização ou homogeneização da forma de pensamento em alguns campos. A estabilização da monogamia, dessa forma, apesar de ter permitido o monopólio sobre o outro, cerceou a liberdade dos cônjuges. De outra forma, enquanto os casais monogâmicos nutrem o desespero da continuidade, os não monogâmicos convivem com a riqueza da diversidade de parceiros e as possibilidades geradas pelas diferentes trocas.

Nesta adesão à manada, a "normose" ou o "comportamento de grupo" substituiria ilusoriamente o vazio deixado pela tradição. Com medo da liberdade e dos riscos inerentes a ela, muitos de nós colam no grupo. Seja ele do tipo que for: religioso, corporativo, profissional, cultural, intelectual, político, de orientação sexual ou até esportivo. Cada um deles garante, ainda que de forma muito mais frágil do que a tradição, um certo jeito de se comportar e de se vestir, um tipo de ambiente a frequentar, temas que merecem ser debatidos, gêneros de lazer e de viagens para as férias e para os fins de semana, crenças para compartilhar e até bens para adquirir. (Brum, 2011, [s.p.])

A adesão a uma normatização, ou ao que é considerado como "natural" ou "normal" em nossa sociedade, parece ser uma fuga à reflexão sobre o status quo. Ao sofrer com preconceitos e cerceamentos impostos por proselitistas monogâmicos (ativistas invisíveis das expressões do "amor romântico"), os agentes sociais relacionam-se conforme regras que por vezes sequer perceberam ter sido impostas, por estarem socialmente sedimentadas. ${ }^{7}$ Talvez muito mais por apego às tradições e à falta de estímulos para repensar a validade de modelos antigos, há casais que vivem a experiência amorosa com apenas um parceiro, mesmo sentindo-se infelizes.

O amor romântico, bastante presente nos produtos veiculados pela mídia (tais como novelas, filmes ou romances), é resultado de toda uma mudança de mentalidade. Porém, apesar de seu inicial potencial revolucionário, na atualidade apresenta-se como problema diante das múltiplas escolhas que podem ser realizadas nas buscas afetivas.

O surgimento do amor romântico esteve ligado à mudança do casamento por interesses financeiros e a alianças entre famílias para a ideia de uma maior liberdade proporcionada pelo casamento pela escolha individual. ${ }^{8}$ Essa nova opção permitiria às pessoas a liberdade de escolher a pessoa pela qual sentissem atração, desejo ou semelhança. O amor romântico, embora alavancado a partir do século XX, está presente há muito mais tempo na história ocidental, mais especificamente desde o século XII.

O amor romântico é um produto extremo de séculos sobre séculos de influência cristã; e, tanto quanto à sua substância, como quanto à sequência do seu desenvolvimento, pode ser dado a conhecer a quem não o perceba comparando-o com uma veste, ou traje, que a alma ou a imaginação fabriquem para com ele vestir as criaturas, que acaso apareçam, e o espírito ache que lhes cabe. Mas todo o traje, como não é

\footnotetext{
7. Conforme Laclau (1979, p. 168), "uma classe é hegemônica não tanto na medida em que é capaz de impor uma concepção uniforme do mundo ao resto da sociedade, mas na medida em que consiga articular diferentes visões de mundo de forma tal que seu antagonismo potencial seja neutralizado". Esse mesmo discurso serve para a monogamia, que raramente é questionada, principalmente pela área acadêmica.

8. Conforme Lins (2007, p. 58), "o amor cortês foi a primeira manifestação do amor como hoje o conhecemos, uma relação pessoal. Tendo surgido no século XII com os trovadores pertencentes à nobreza da Provença, mais tarde se estendeu a outras regiões da Europa". Esse grupo era composto por homens celibatários, detentores de um código de amor cavalheiresco, que sofriam por amor e desbravavam horizontes em busca de donzelas. Desde o século XVIII, entre as mudanças ocorridas, "a mais importante de todas, sem dúvida, reside na passagem do casamento 'de razão', com finalidade econômica e, em geral, organizado pelos pais ou, por intermédio deles, pela comunidade urbana a que pertenciam, a um casamento por amor, livremente escolhido pelos próprios cônjuges" (Ferry, 2007, p. 115). Essa mudança é vista na atualidade ainda como uma liberdade, e não como uma prisão, pois poder escolher livremente seu parceiro seria a possibilidade de aproximar-se de uma felicidade idealizada.
} 
eterno, dura tanto quanto dura; e em breve, sob a veste do ideal que formamos, que se esfacela, surge o corpo real da pessoa humana, em quem o vestimos. O amor romântico, portanto, é um caminho de desilusão. (Pessoa, 1997, p. 45)

Desilusão ou não, o amor romântico parece ser um bom argumento para a manutenção da monogamia no imaginário atual. Conforme praticantes da rede $\mathrm{RLi}$, uma das principais críticas a essa forma de relacionamento, o amor romântico é projetivo e irreal. Dessa forma, poder-se-ia afirmar que o amor romântico, inicialmente entendido como uma prática progressista e libertadora, atualmente possui características reacionárias, aprisionando os casais a uma ideia de "completude" que dificilmente é encontrada em uma única pessoa.

\section{O amor-consumo: um negócio rentável}

$\mathrm{Na}$ atualidade, pressupondo a emergência do indivíduo independente, ou até mesmo da figura do self made man, pode-se entender que a busca pelo amor é uma jornada de realização individual. O sucesso ou o fracasso no amor depende exclusivamente das ações e das estratégias adotadas pelo indivíduo. $\mathrm{O}$ estabelecimento das redes de relação e a solidez dos laços são resultado dos empreendimentos realizados por esse indivíduo dotado de múltiplas capacidades e livre para estabelecer suas próprias conexões. Porém, pode-se indagar: até que ponto existe essa liberdade? Como se dá o crédito ou o débito em relação ao amor? Levando-se em consideração elementos subjetivos como atração, desejo ou "química", como eles podem estar relacionados com as lógicas de troca e de valor? Como materializar a imaterialidade ou mensurar um valor pessoal?

Ao questionar o valor do amor (valor central na constituição de diversas religiões, como as de tradição judaico-cristãs), poder-se-ia compreender que há uma relativização do valor do ser humano, ao entender esse sentimento como algo intrínseco a todos os seres. Dessa forma, todos os seres seriam capazes de amar. Ao partir dessa premissa, pode-se considerar que todos os seres poderiam empreender essa busca, porém, não se pode negar que esse amor pode ser percebido em diversas variações e expresso de diferentes formas.

Se em nossa sociedade pós-moderna a aquisição de bens de consumo permeia as relações e os laços entre os indivíduos, deve-se considerar, porém, que a compra desses bens é realizada com a utilização do dinheiro. Este traz consigo diversos outros elementos a ser desvendados, a fim de que se possa compreender melhor o contexto histórico e social. ${ }^{9}$

Poder-se-ia então indagar se o amor, em nossa sociedade, assim como o dinheiro, é trocado por diferentes valores, tais como: segurança, autoestima, realização financeira, satisfação sexual, hedonismo e ascese espiritual. Quais seriam os outros valores (subjetivos) que estariam relacionados com o amor? Qual a relação entre dinheiro e relacionamentos?

Nem sempre é possível "educar" sentimentos e controlar emoções. Ao contrário do dinheiro, algo que aparentemente é palpável e controlável a partir da racionalidade e do cálculo direto, os cálculos elaborados no plano subjetivo se processam de maneira diferente, e nem sempre conforme o esperado. Inúmeros são os fatores que tornam os sentimentos e as subjetividades imprevisíveis, complexificando ainda mais as previsões.

Dessa maneira, podemos assim elucidar a constituição de um "mercado do amor romântico", o qual abordará questões que o constituem, como preço e valor. ${ }^{10} \mathrm{Na}$ tentativa de racionalizar os relacionamentos amorosos na atualidade, poder-se-ia realizar uma breve abstração, que consideraria que no mundo globalizado até mesmo o amor se transformou em um negócio. Esse negócio é realizado entre fornecedores e consumidores de diferentes regiões e culturas.

O papel de consumidor ou de fornecedor pode ser assumido por cada agente social conforme suas necessidades, porém, por vezes esses não possuem as características mais adequadas às expectativas dos demais agentes. A qualidade do "produto" pode ser inferior à desejada, os prazos podem não ser suficientemente rápidos ou até mesmo o preço cobrado pelos serviços e "produtos" podem ter uma relação custo-benefício muito baixa. Para Maciel (2008), o contexto de hiperescolha nos torna infiéis à marca, à mercê da múltipla influência da variedade de opções, aumentando angústias e dúvidas quanto ao que seria a melhor "compra".

Maciel (2008) afirma haver uma segmentação no "mercado dos relacionamentos", no qual há pessoas

9. Conforme Zélizer (2009), não há como separar o sujeito do sentimento, assim como não há como separar o sujeito das trocas (sejam elas mercantis ou não mercantis). Há também uma ligação bastante íntima entre o conjunto de relações sociais estabelecidas em espaços domésticos e públicos: um age sobre o outro.

10. O preço, conforme Zélizer (1992, p. 498), é "expresso em uma quantia específica de dinheiro", enquanto o valor "abarca elementos qualitativos". Valorativamente, poder-se-ia dizer que o amor possui um preço, ou apenas expressaria um valor vivenciado nas práticas cotidianas? Conforme exposto nas páginas a seguir, talvez se possa afirmar que o preço seja também uma expressão que possa definir o valor pessoal dos agentes envolvidos no que aqui é denominado "mercado amoroso". 
que compartilham de uma ou mais características psicológicas e valorizam determinados atributos no "produto" (objeto de desejo ou sujeito) ambicionado. Porém, nem todos os consumidores e produtores do mercado amoroso ${ }^{11}$ são bem-sucedidos em seus empreendimentos.

Há alguns que utilizam empresas de relacionamentos para auxiliá-los nessa empreitada. Elas são responsáveis por fornecer dicas e regras aos que desejam ser mais bem sucedidos nesse mercado. Orientam seus clientes sobre posturas e práticas que devem ser tomadas para maximizar as chances de terem seu produto bem posicionado nas "vitrines" (bares, boates e outros ambientes sociais), para terem uma boa visibilidade e conquistarem a simpatia até mesmo da mais exigente clientela. ${ }^{12}$ Para Maciel (2008), o produto (o parceiro que está inserido no "mercado amoroso") pode sofrer diversas adaptações em função das necessidades do mercado, ganhando reputação, acirrando a concorrência e conquistando novas praças (onde o produto é apresentado ao público).

No início, esse "ethos empreendedor" pode sofrer conflitos com o ethos religioso, os quais se contradizem. Ao mesmo tempo em que o amor romântico pressupõe a lógica de um amor sublime e para a vida toda, há outras opções no mercado amoroso, como o poliamor ou as relações livres, práticas sexuais e afetivas que permitem uma maior diversificação, alimentando um constante reposicionamento da marca perante os demais parceiros. Há diversas modalidades de "segmentação" nesse "mercado", nas quais estariam os diferentes grupos sociais que antes eram excluídos pela adoção apenas da monogamia como forma de relacionamento.

Tais formas de segmentação, ou seja, grupos de pessoas que se identificam por ter as mesmas práticas e hábitos, serão explicadas a seguir. Entre os diferentes grupos não monogâmicos, estão presentes, na cultura rio-grandense e brasileira, suingueiros, casais abertos, assexuados, RLis e poliamoristas. A diferença entre eles refere-se à liberdade sexual ou afetiva dos indivíduos envolvidos nos relacionamentos (casuais ou prolongados), bem como à visibilidade e/ou ao reconhecimento dos outros parceiros.

Conforme Castro e Araújo (1977), na atualidade pode-se falar de uma fusão de individualidades. ${ }^{13}$ Essa noção moderna de indivíduo-valor atribuída pelos autores é vista de outra maneira por Dumont
(1985), que separa os agentes sociais segundo a visão de individualismo e de holismo, conceitos nos quais se entende, respectivamente: o indivíduo, como valor, e o sujeito, como pertencente a uma coletividade. Nas relações não monogâmicas, porém, não se pode afirmar claramente a relação entre individualismo e coletividade, pois esses indivíduos empreendem suas escolhas por causa da ampliação de permissões sociais no espectro de possibilidades e opções disponíveis.

Não apenas nas relações monogâmicas, como também nas não monogâmicas, a relação de ofertar não é apenas passiva; ela conta também com as exigências e necessidades do indivíduo que empreende a ação. Com o passar do tempo, a aquisição de uma maior confiança permite que essas relações adquiram outros níveis, que haja um aprofundamento dos laços e, consequentemente, um aumento dos riscos nas ações. Esses riscos envolvem interesses e sentimentos de ambas as partes, mas também riscos socialmente conhecidos, os quais são mediados em negociações previamente estabelecidas.

Na medida em que a confiança reduz a complexidade social, o sistema amoroso é sustentado dentro de determinada ordem social, mesmo que o vínculo amoroso por si mesmo não responda aos anseios da confiança, devendo-se considerar os objetos, os sujeitos e o tempo, ou seja, as dimensões da complexidade social. (Zamboni, 2011, p. 298)

Nesse mercado, a adoção de boas estratégias de relacionamento podem render lucros ou gerar débitos que serão cobrados futuramente. As estratégias adotadas envolvem uma série de ações que aparentemente não são intencionais, mas que já estão orientadas com uma lógica protetiva. As ações, previamente calculadas, podem resultar em ganhos, mas possuem seus riscos. "Prudência, sim, mas isso não significa esterilizar nossas vidas, evitar correr riscos a qualquer custo? [...] Desprendimento, sim, mas será mesmo necessário renunciar aos laços de amizade e amor?" (Morin, 2008, p. 8).

Investimentos financeiros podem ser feitos na compra de outros materiais que valorizem o produto, tais como acessórios ou produtos com marcas que proporcionem distinção social (Bourdieu, 2007). Em relação aos relacionamentos amorosos, as marcas e traços visivelmente apresentados nos encontros não

11. Indo além da expressão mercado amoroso, poder-se-ia também utilizar a expressão mercado dos relacionamentos, a qual não estaria ligada a uma ideia de amor, mas que também estaria relacionada com a ideia de amor-consumo, referente a um aumento da segmentação de grupos e da satisfação de um mercado que visa a diversos tipos de consumidores-produtores. Os jogos de sedução e a valorização da imagem pessoal, socialmente exposta, parecem ser elementos presentes tanto nas relações monogâmicas quanto nas não monogâmicas.

12. Conforme Maciel (2008, p. 41) "cada vez mais vemos pessoas usando blogs, comunidades virtuais e mesmo jornais para anunciar suas 'disponibilidades'".

13. Percebe-se haver, assim como Bauman (2004, p. 6) afirma, um "amor líquido", conceito proveniente da "bênção ambígua" da "individualização". 
apenas representam a personalidade que se pretende externalizar, mas também reforçam elementos distintivos relacionados ao status social do indivíduo. Neste sentido, poder-se-ia acrescentar a importância de um possível goodwill ${ }^{14}$ nas relações amorosas.

Entretanto, nem todos os agentes priorizam a maximização dos ganhos a partir de atributos exteriores. Há agentes que, por autoavaliarem a lacuna em termos de habilidades sociais ou até mesmo sentimentais, preferem engajar-se em relacionamentos com menores custos (financeiros ou sentimentais). Para Maciel (2008), os relacionamentos não são apenas regidos pela esfera da racionalidade e do planejamento:

Feliz ou infelizmente, os indivíduos não têm consciência de todos os aspectos psicológicos envolvidos no seu processo de decisão: necessidade de aceitação e de ajuste social, carências, transtornos de personalidade, compensação de frustrações e mesmo estado de humor, entre outros. (p. 77)

Com a ampliação da liberdade de expressão com mídias sociais, tais como Facebook, Instagram e Twitter, bem como com a agilidade proporcionada pela comunicação móvel (laptops, smartphones, tablets), a expressão da linguagem torna-se mais ampla, abarcando os diversos grupos sociais. $\mathrm{O}$ cidadão pode ser entendido na atualidade como um "prosumer", tanto produtor (producer) quanto consumidor (consumer). Esses indivíduos são bricoleurs de posições éticas, estéticas e políticas. Apropriam-se de diferentes elementos e formas de pensar, construindo discursos próprios, e podem agregar e expressar diferentes formulações rapidamente. ${ }^{15}$

Sexo, poder e dinheiro possuem interligação entre si desde muito tempo, porém, as relações entre eles foram alteradas conforme as sociedades e os contextos históricos. Os relacionamentos, de certo modo, estão intimamente ligados às formas de pensamento e de organização social.

$\mathrm{Na}$ atualidade, os relacionamentos afetivos estão relacionados ao sentimento e à escolha, fortalecendo as decisões individuais - por causa do aumento da liberdade de expressão das subjetividades. As decisões pessoais não deixam de considerar fatores sociais - tais como as diferenças de etnia e capitais sociais ou econômicos, mas conseguem mediar mais livremente entre as necessidades próprias e as imposições sociais.

\section{A não monogamia: contraposição ao modelo social vigente}

Sobre os grupos não monogâmicos, anteriormente citados como integrantes de uma segmentação do mercado de relacionamentos, é necessário fazer uma distinção entre seus membros. Entre eles, serão descritos, a seguir, os suingueiros, os casais abertos, os assexuados, os RLis e os poliamoristas.

Proveniente da expressão inglesa swing, o grupo chamado suingueiros também denomina sua prática como "troca de casais". Esses casais permitem a liberação sexual em ambientes específicos e durante períodos de tempo específicos. O objetivo dessas duplas é a experimentação sexual com outros grupos de pessoas, porém, sem a manutenção de laços afetivos. $\mathrm{O}$ suingue possui regras determinadas, em que os participantes se limitam às práticas sexuais junto com seus companheiros e de maneira esporádica.

Os casais abertos são aqueles em que há uma espécie de contrato entre os parceiros, um consenso sobre uma liberdade restrita, a qual permite o estabelecimento de outras relações, porém, sendo estas entendidas e tratadas como secundárias e invisíveis.

Os poliamoristas, adeptos do poliamor, são pessoas que possuem dois ou mais relacionamentos sexuais ou afetivos, mantendo fidelidade aos parceiros reconhecidos. Pode-se perceber a existência de divergências ideológicas entre as visões de poliamoristas e adeptos das relações livres. Estes, ao contrário da exclusividade poliamorista (chamada também de polifidelidade), entendem os indivíduos como completamente livres para realizar as associações sexuais/ afetivas que desejarem, sem solicitar permissões ou submeter-se a controles - o sujeito é agenciador de seu tempo e afeto.

Relações Livres é o nome do movimento social originado no Rio Grande do Sul e que se autodenomina como uma rede ${ }^{16}$ pois estabelece ligação entre os demais grupos não monogâmicos. Atualmente, o grupo também possui o início de uma ligação com

14. "O goodwill pode ainda ser definido como uma espécie de mais-valia, resultante de um valor agregado em função da lealdade dos clientes, da imagem, da reputação, do seu nome, da marca dos seus produtos, da política comercial, das patentes registradas, dos direitos exclusivos de comercialização, da formação e habilidade dos funcionários, entre outros" (Lamelas, 2007, p. 39; grifos do autor). O goodwill de uma empresa está intimamente ligado a previsões de ganhos futuros.

15. "Na perspectiva do fortalecimento do capitalismo, a proposta neoliberal busca uma abertura política que possa assegurar a liberdade de ação do capital. Assim, essa liberdade rege todas as relações mercadológicas e transforma necessidades sociais em produtos que podem ser comercializados e consumidos" (Lima, 2005, p. 45).

16. No Brasil, essa rede possui maior número de adeptos no estado do Rio Grande do Sul, e atualmente tem articulado com os demais movimentos a realização do I Encontro Nacional das Relações Não Monogâmicas. 
os assexuados. ${ }^{17}$ Os adeptos do Relações Livres, os RLis (lê-se errelís), são entendidos como pessoas autônomas e livres para expressar sexual e afetivamente seus desejos com quaisquer indivíduos. Os RLis não realizam acordos, não invisibilizam relacionamentos e, em grande parte, sustentam um padrão de vida financeiramente independente de seus parceiros.

Para todos os grupos, o sentimento que se contrapõe ao ciúme (ligado à ideia do amor romântico) é a compersão. Esta é vista como um componente do amor, em que as experiências do outro companheiro (seja ele reconhecido ou não) tornam-se a felicidade daquele que, socialmente em uma relação monogâmica, deveria sentir ciúmes. A compersão entende os demais elos afetivos como enriquecedores e promotores da felicidade de todos os envolvidos.

Os integrantes do Relações Livres ainda deliberam sobre diversas questões relacionadas à maneira como apresentar sua prática cotidiana a outros grupos. Geralmente nos fins de semana são realizadas reuniões com grupos de trabalho de temáticas previamente determinadas, em que experiências são compartilhadas e os novos ingressantes (chamados de novos amigos) são recebidos no grupo. Expressões são pensadas, questões são levantadas e o consenso determina novos conceitos que serão adotados pelos integrantes do movimento.

Porém, no grupo RLi, mesmo sem um consenso total, a utilização da expressão "amor" é suprimida, dada à forte associação ideológica que possui com o ideal de amor romântico. Até o momento, a rede considera o "amor" um problema conceitual, mesmo sem ter definido outra expressão que defina o sentimento existente entre os seus praticantes. Para o grupo, os relacionamentos por eles estabelecidos são livres das irrealidades projetivas do amor idealizado, presente em grande parte dos produtos culturais da atualidade. Dessa forma, o ciúme não pode organizar a relação do casal, e sim os objetivos comuns, a afetividade ${ }^{18} \mathrm{e}$ o sexo. Conforme afirmação de um dos integrantes RLi, concedida em entrevista,

as pessoas desvalorizam (as relações livres), afirmando que não é amor, mas nós temos relações afetivas com dedicação e intensidade que não perdem em nada para as demais. Não há nenhum 'amorômetro' que possa medir isso. Não há unidade de medida. Tem que se entender que tipo de relação que se quer construir. ${ }^{19}$
Neste sentido, cabe a afirmação de Le Breton (2009, p. 111), para o qual "o homem está afetivamente presente no mundo. A existência é um fio contínuo de sentimentos mais ou menos vivos ou difusos, os quais podem mudar e contradizer-se com o passar do tempo e de acordo com as circunstâncias". A instituição de "diversos amores" ou "diversos parceiros" é entendida pelos RLis como uma prática "natural", uma tentativa de aumentar as possibilidades de que algum dos relacionamentos estabelecidos dê certo e que as possibilidades de satisfação sejam aumentadas. Conforme outro depoimento de um RLi praticante, "neste tipo de relacionamento, a conversação e a confiança são os pilares. As regras estabelecidas pelos casais são flexíveis e resultantes de uma negociação". É uma postura semelhante ao laissez faire, em que cada um pode agir conforme desejar, sem a regulação de um mercado de práticas.

Os adeptos do Relações Livres partem do pressuposto de que a sociedade atual não permite o diálogo e a indagação da monogamia. Tais como os argumentos que sustentam a heteronormatividade como prática socialmente aceita, para os RLis, existe uma ideologia vigente para impor a monogamia. Dessa forma, o movimento não monogâmico propõe colocar-se em contraposição à estrutura social atual, renunciando à monogamia e à situação de infelicidade às quais se submetem casais que moram juntos, por causa das coerções sociais. Tal infelicidade é percebida por alguns integrantes do grupo como derivada do tédio (instituído pela rotina), da mentira (de que não há desejo ou atração por outras pessoas) e da dissimulação (de que o ideal romântico e de ilusão é algo verdadeiro e eterno).

A rede de relações não monogâmicas parte do pressuposto de que os casais, quando formados, não possuem como indagação inicial se o relacionamento será monogâmico ou não, pois de uma maneira implícita todos os relacionamentos partem de um marco inicial monogâmico. Essa rede não monogâmica entende que o casamento é uma instituição que perpetua o costume e a tradição de algo que foi determinado socialmente há vários anos, mas que tem sofrido alterações em termos de práxis (ao menos discursiva). "Não é fácil compreender como, em que extensão, profundidade e intensidade, as alienações que brotam da propriedade privada atuam sobre nossos sentimentos e emoções mais íntimas, pessoais" (Lessa, 2010, p. 5-6).

$\overline{17 .}$ Os assexuados, apesar de não terem interesse na realização do sexo (mesmo esporadicamente o praticando, em grande parte por pressão de parceiros), são pessoas livres para se relacionar com outras, na busca por carinho e afeto. Todos os movimentos não monogâmicos parecem realizar uma contraposição à estrutura social existente, denunciando uma moral impositiva e restritiva aos agentes sociais.

18. "A afetividade é aquilo que, ao mesmo tempo, nos cega e nos ilumina, mas a afetividade humana inventou algo que não existia: o ódio, a maldade gratuita, a vontade de destruir por destruir. Homo sapiens é igualmente homo demens. Se pudéssemos dizer: somos $50 \%$ sapiens, $50 \%$ demens, com uma fronteira no meio, isso seria muito bom. Mas não há fronteira nítida entre os dois" (Morin, 2008, p. 53).

19. Entrevista concedida à autora e registrada em diário de campo, em julho de 2011. 
Conforme a opinião de um entrevistado RLi, ele acredita que deverá haver uma superação do modelo de família, de monogamia e também de poligamia. Afirmou ainda defender mudanças no modelo social e econômico atual, organizando a vida comunitária de maneira diversa do sistema de heranças atual. Para ele, a atual hegemonia cultural da monogamia ocidental impõe o namoro como uma "preparação para o casamento", e como um "ensaio para a constituição de uma família" heterossexual. Esse RLi entende a família como uma invenção sociocultural; a religião, como uma prisão espiritual; e o namoro, como um "treino para a vida a dois".

Tais visões estavam fundamentadas em uma ideia de superação do atual modelo econômico. "A superação do casamento monogâmico, pela qual lutam os comunistas, é a passagem para a mais livre e plena realização afetiva das pessoas - analogamente a como a superação da propriedade privada abrirá as portas a um desenvolvimento muito superior da sociedade" (Lessa, 2010, p. 7).

Para a coordenação do movimento RLi, o casamento é o momento ritual da família monogâmica, cujo modelo está fragilizado, perdendo seu poder. Sua degradação é vista como positiva, em busca de uma honestidade não presente em relações monogâmicas infelizes, nas quais a traição é motivo de sofrimento para os parceiros e há um constante cerceamento da liberdade.

Dessa forma, as propostas RLi podem ser brevemente resumidas com o que pontua Lessa (2010, p. 7):

Não defendemos o descompromisso afetivo e pessoal que caracteriza algumas propostas de "amor livre", assim como recusamos o moralismo monogâmico hoje predominante. Estamos propondo que as relações amoross [sic] devam ser pautadas apenas e tão somente pelas decisões livres, emancipadas, das pessoas. Para isso, como veremos, é preciso superar a sociedade de classes com tudo o que ela implica: o Estado, a violência, a miséria, a exploração do homem pelo homem, as guerras, a propriedade privada, a destruição ecológica... e o patriarcalismo.

A prática das relações livres está baseada na confiança, na verdade (sem o ocultamento de outros relacionamentos) e na superação do ciúme e da possessividade dos parceiros. O movimento social não monogâmico vai na contramão da privatização dos afetos, defendendo a liberdade de expressão plural, baseada na expressão social de escolhas individuais. Conforme integrantes do movimento não monogâmico, a estrutura social determina a dinâmica: limita, impõe, cerceia, tendendo a levar ao ciúme e à violência.
O amor, na atualidade, está ligado não apenas à sua própria representação ou à maneira como o conceito é apropriado pelos diferentes grupos, mas também está associado a três fatores: a incerteza, a complexidade e a diversidade. Para Bauman (2004, p. 11), "o amor é afim à transcendência; não é senão outro nome para o impulso criativo e como tal carregado de riscos, pois o fim de uma criação nunca é certo".

Se anteriormente se poderia afirmar que os vínculos estavam baseados em ligações firmes, confiáveis e apoios estáveis, na atualidade a assistência do cônjuge ou da descendência genealógica colocam-se em bases instáveis. "Quanto mais o casamento se liberta de seus motivos tradicionais, econômicos ou familiares, se tornando fator de escolha individual e afinidade eletiva, mais ele se choca com a questão tipicamente moderna do "desgaste do desejo"' (Ferry, 2007, p. 126-127).

A visão dos grupos não monogâmicos não apenas se apresenta como outra forma de expressão dos afetos (sejam eles chamados de amor ou não), mas também se contrapõe discursivamente ao modelo econômico e social vigente. A socialização dos afetos mostra-se como contraposição à privatização, de tal forma que a liberdade do consumidor-produtor (própria do sistema capitalista) é apropriada pelo movimento não monogâmico para gerar liberdade de escolha nas relações afetivas/sexuais.

Segundo a proposta RLi, a organização familiar e as instituições patriarcais seriam, assim, rearranjadas. A superação do casamento e a instituição de relacionamento sem vínculos baseados em projeções irreais e expectativas de posse apontam para uma liberdade que começa a ser vivenciada no plano discursivo, com a facilidade da livre expressão de pensamentos de diferentes grupos nas redes sociais.

Ao indagar de um praticante do Relações Livres sobre o porquê de ter adotado essa prática, ele afirmou que pessoalmente não acredita na existência de uma única pessoa no mundo que reúna todas as qualidades de que ele necessita. Portanto, para se sentir mais completo, ele pode assumir diversas personalidades e atuar de diversas maneiras (como se fossem distintas personas) com as diferentes parceiras. Ele entende que as características psicológicas de cada uma são diferentes e que cada uma seria "boa para uma coisa". Esse RLi afirmou "aproveitar o que há de melhor em cada uma".

Essa intermediação, porém, não é isenta de conflitos e intervenções. No caso acima relatado, ao saberem da existência das outras parceiras, houve a tentativa de aproximação das "concorrentes" (em uma relação a três), assim como a tentativa de conquistar o homem apenas para si, com o intuito de obter toda a atenção no relacionamento (superando as adversárias). Esse caso é apenas um dos existentes, mas as relações 
entre homens e mulheres podem ser gerenciadas conforme as necessidades de cada RLi.

As relações livres, conforme esse interlocutor, parecem ser uma maneira de estabelecer diversos vínculos com outras pessoas, de forma a criar uma grande rede de conexões que permita a fuga da solidão. Em virtude da falta de tempo e talvez até mesmo por não ter habilidade de encontrar uma pessoa que aceite todas as imperfeições próprias, e por desejar uma pessoa o mais completa possível, esse RLi entende não ser necessário ficar restrito ao relacionamento monogâmico. Ele afirma lidar com as diferenças de aceitação das parceiras, havendo comportamentos e situações que uma aceitaria melhor que as outras. Assim, passou a organizar seu tempo de maneira a tentar suprir as necessidades delas e de suas próprias.

A rede de relações por ele estabelecida lhe permite não apenas escolher com quem deseja ficar, mas também aproveitar as opções disponíveis no mercado amoroso, sem prender-se à fidelidade da marca (ou de apenas uma pessoa), empreendendo suas escolhas conforme as necessidades que possui e as disponibilidades que se apresentam. Quando deseja "um papo mais cabeça" encontra-se com uma parceira; quando quer "um sexo mais selvagem", busca outra; e quando quer "um carinho", procura uma terceira. O estabelecimento de diversos vínculos permite-lhe não apenas sentir-se mais satisfeito nessa rede de relações, mas também evitar a sensação de "desmoronamento do mundo" que ocorre quando do rompimento de uma relação monogâmica, em que diversos empreendimentos (financeiros/afetivos/temporais) foram realizados.

A facilidade das trocas afetivas ou sexuais proporcionadas pela agilidade dos contatos e da formação de redes não tem apenas tornado o amor mais informal (permitindo um fluxo de pensamentos e conexões entre indivíduos que questionem a norma), mas também reafirma a possibilidade de outras formas de expressão do afeto, que discursivamente podem possuir outros nomes, mas que em sua essência primam pela liberdade: de opção, de movimentação, de consumo, de tempo despendido ou de intensidade dedicada.

Hoje em dia há uma mudança social com relação às formas de amor e relacionamentos. Essas mudanças são um reflexo das próprias modificações geradas pelos contextos globais e locais, inseridos na lógica capitalista. Esses novos híbridos e as novas possibilidades permitem às pessoas uma infinidade de alternativas e opções. Nesse ambiente surgem formas de relacionamento opostas à monogamia, as quais questionam os modelos vigentes, promovendo uma reflexão quanto à privatização dos sentimentos.

Seria justo obrigar alguém a amar somente uma pessoa e ignorar seus sentimentos por outras pessoas que também a fazem feliz? Diante dessa possibilidade de adaptação dos relacionamentos às necessidades de cada sujeito, outros grupos se propõem a estabelecer redes de relacionamentos diferentes das que são convencionadas pela sociedade, buscando, dessa forma, promover outras formas de amor/afetividade. Neste sentido, pode-se acrescentar o trecho da música " $O$ que eu também não entendo", interpretada pela banda brasileira Jota Quest, que engloba diversos aspectos dos relacionamentos na atualidade: "Afinal, será que amar é mesmo tudo? Se isso não é amor, o que mais pode ser?" As diferentes formas de expressar o afeto podem adquirir diferentes nomes e formas de organização, mas seria isso capaz de mudar o significado das trocas e a necessidade de interação entre os sujeitos?

\section{Referências}

BAUMAN, Zygmunt. Amor líquido: sobre a fragilidade dos laços humanos. Rio de Janeiro: Jorge Zahar, 2004.

BOURDIEU, Pierre. A distinção: crítica social do julgamento. São Paulo: Edusp/ Porto Alegre: Zouk, 2007. BRUM, Eliane. A doença de ser norma. Revista Época, 18 de julho de 2011. Disponível em: <http://revistaepoca. globo.com/Revista/Epoca/0,,EMI249779-15230,00A+DOENCA+DE+SER+NORMAL.html>. Acesso em: 19 jul. 2011.

CASTRO, Eduardo Viveiros de; ARAUJO, Ricardo Benzaquem de. Romeu e Julieta e a origem do estado. In: VELHO, Gilberto. Arte e sociedade: ensaios de sociologia da arte. Rio de Janeiro: Jorge Zahar, 1977. p. 130-169.
DUMONT, Louis. Sobre a ideologia moderna. Gênese, I. $\mathrm{O}$ individualismo - uma perspectiva antropológica da ideologia moderna. Rio de Janeiro: Rocco, 1985. p. 35-71. FERRY, Luc. O homem-Deus, ou o sentido da vida. Rio de Janeiro: Difel, 2007.

LACLAU, Ernesto. Política e ideologia na teoria marxista. Rio de Janeiro: Paz e Terra, 1979.

LAMELAS, António José Oliveira. Goodwill - breves reflexões. Temas de contabilidade, fiscalidade, auditoria e direito das sociedades. 2007. p. 37-49. Disponível em: <http:// www.jmmsroc.pt/downloads/10anos/02.pdf>. Acesso em: 12 mar. 2012.

LE BRETON, David. As paixões ordinárias: antropologia 
das emoções. Petrópolis, RJ: Vozes, 2009.

LESSA, Sergio. Abaixo a família monogâmica! 2010. Disponível em: $\quad<$ http://pt.scribd.com/doc/58174623/Abaixo-aFamilia-Monogamica>. Acesso em: 12 mar. 2012.

LIMA, Elma Corrêa de. Tema transversal: uma questão de inovação ou mudança? In: LOVISARO, Martha; NEVES, Lecy Consuelo. Futebol e sociedade: um olhar transdisciplinar. Rio de Janeiro: EdUERJ, 2005.

LINS, Regina Navarro. A cama na varanda: arejando nossas ideias a respeito de amor e sexo: novas tendências. Rio de Janeiro: Bestseller, 2007.

Entrevista. Poliamor: o fim do amor romântico e a era do relacionamento aberto. Entrevistador Ruleandson do Carmo. Blog E quot. Eu só queria um café... 30 de agosto de 2009. Disponível em: <http://www.eusoqueriaumcafe. com/2009/08/entrevista-poliamor-o-fim-do-amor. html>. Acesso em: 17 jul. 2011.

LOYOLA, Maria Andréa. Sexo e sexualidade na Antropologia. In: LOYOLA, Maria Andréa (Org.). A sexualidade nas Ciências Humanas. Rio de Janeiro: EdUERJ, 1998. p. 17-48. LUHMANN, Niklas. O amor como paixão. Lisboa: Difel, 1991.

MACIEL, André Figueiredo. A fila anda: mas não empurra que é pior: uma abordagem de marketing sobre relacionamentos amorosos. Porto Alegre: Fábrica de Leitura, 2008. MEZAN, Renato. O amor romântico no século XXI. Estudos e Pesquisas 234, [XX Fórum Nacional (2008) Brasil - "Um Novo Mundo nos Trópicos": 200 Anos de Independência Econômica e 20 Anos de Fórum Nacional (sob o signo da incerteza)]. Disponível em: <http://www. inae.org.br/sec.php?s=410\&i=pt $>$. Acesso em: 21 abr. 2011. MORIN, Edgar. Amor, poesia, sabedoria. Rio de Janeiro: Bertrand Brasil, 2008.

PESSOA, Fernando. Livro do desassossego. Lisboa: Assírio \& Alvim, 1997. Disponível em: <http://www. planonacionaldeleitura.gov.pt/clubedeleituras/upload/e_ livros/clle000022.pdf>. Acesso em: $1^{\circ}$ ago. 2011.

PISCITELLI, Adriana; ASSIS, Glaucia de Oliveira; OLIVAR, José Miguel. Gênero, sexo, amor e dinheiro: mobilidades transnacionais envolvendo o Brasil. Campinas: Ed. Unicamp, 2011.

SIMMEL, Georg. Filosofia do amor. São Paulo: Martins Fontes, 1993.

ZAMBONI, Marcela. São demais os perigos dessa vida, pra quem tem paixão. Do perigo ao risco no amor em Niklas Luhmann. RBSE 10 (29), agosto de 2011, p. 275300. Disponível em: <http://www.cchla.ufpb.br/rbse/ Index.html>. Acesso em: 30 jul. 2011.

ZÉLIZER, Viviana. Repenser le marché: La construction sociale du 'marché aux bébés' aux États-Unis, 1870-1930. Actes de la Recherche en Sciences Sociales, n. 94, p. 3-26, set. 1992. 256, 2009.

Dualidades perigosas. Mana, v. 15, n. 1, p. 237-

ZERO HORA. Pesquisa aponta que casais preferem manter relacionamento após uma traição. 21 de janeiro de 2009. Disponível em: <http://zerohora.clicrbs.com.br/zerohora/jsp/default.jsp?.uf=1\&local=1\&section=Estilo\%20 de\%20Vida\&newsID=a2414013.xml>. Acesso em: 30 jul 2011.

\title{
¿El fin del amor romántico o uno nuevo amor-consumo? Una breve discusión sobre las nuevas formas de relaciones de la sociedad capitalista occidental actual
}

\section{Resumen}

\begin{abstract}
Este artículo aborda el concepto de amor-consumo y otras expresiones de afecto en la sociedad contemporánea, basado en el pensamiento económico actual sobre las relaciones que se oponen al ideal del amor romántico. El texto, de orientación antropológica, presenta entrevistas de miembros de un nuevo movimiento social auto-titulado Relaciones Libres, que considera el individuo como gestor de sexo y amor, en contra de la monogamia.
\end{abstract}

Palabras clave: amor, consumo, relaciones, capitalismo, monogamia. 
The end of romantic love or a new love-consumption? A brief discussion on new forms of relationships of current western capitalist society

Abstract

This paper discusses the concept of love-consumption and other expressions of affection in contemporary society, based on the current economic paradigms regarding the relationships that oppose the ideal of romantic love. The Material, via anthropological approach, presents interviews of members of a new social movement self-titled Free Relations, which considers the individual as manager of sex and love, contrary to monogamy.

Key words: love, consumption, relationships, capitalism, monogamy.

Data de recebimento do artigo: 9/4/2013

Data de aprovação do artigo: 26/6/2013 